\title{
Upfront triple therapy for pulmonary arterial hypertension: is three a crowd or critical mass?
}

\author{
Michael D. McGoon \\ Affiliations: Mayo Clinic, Rochester, MN, USA.
}

Correspondence: Michael D. McGoon, Mayo Clinic, 200 1st St SW, Rochester, MN 55905, USA. E-mail: mmcgoonamayo.edu

○

@ERSpublications

Upfront triple therapy may be the most reliable treatment strategy that we can offer PAH patients http://ow.ly/ugPbg

Even the most enthusiastic reviews about progress in the pharmacotherapeutic management of pulmonary arterial hypertension (PAH) either begin or conclude with the sad acknowledgement that no treatment strategy comes close to being considered a "cure." There is little doubt, however, that the cumulative discovery, clinical testing, approval and integration of an expanding armamentarium of medications has led to improvement in patients' general well-being and life expectancy. Based on survival as a benchmark, the state of patients with $\mathrm{PAH}$, as well as those with more narrowly and homogeneously defined idiopathic/ heritable/toxin-induced $\mathrm{PAH}$, has progressively improved from when no specific drug treatment was available, to when calcium channel blockers were used, to the introduction and use of intravenous epoprostenol, to the current era, in which multiple drugs are available and are frequently employed in combination [1-8]. Whereas median survival in 1986 for idiopathic PAH (then called primary pulmonary hypertension) was 2.8 years [2], it now exceeds 7 years [1].

The corollary of a beneficially widening array of therapeutic options is the complexity of guiding the multiple possible permutations of their use with an algorithm based on credible clinical studies, experience, and recognition of possible adverse effects as well as of expected degree and type of benefit. The Fifth World Symposium on Pulmonary Hypertension provided an updated treatment algorithm that summarises the options for treatment of PAH of varying degrees of symptomatic severity by World Health Organization (WHO) functional class, and attached a strength of recommendation and level of evidence grade to each group of options [9]. Thus, for example, any of the following medications (listed in politically neutral alphabetical order) are regarded as I-A or B for initial treatment of WHO functional class III PAH: ambrisentan, bosentan, intravenous epoprostenol, inhaled iloprost, macitentan, riociguat, sildenafil, tadalafil, and inhaled or subcutaneous treprostinil. While this guideline appropriately adheres to the conclusions of published studies and regulatory approval of these medications, it leaves open the question that might reasonably be foremost in every clinician's mind: which medication is best? The reasons for this circumspection are interrelated. First, insofar as the studies of different drugs can be compared (allowing for differences in study population, study design and end-points), the differences in clinical benefit are fairly nuanced. The complexity of administration, specific adverse effects and expense may vary, but every drug has its balance of risks and benefit. Secondly, no appropriately designed head-to-head comparison between drugs has been performed.

The question of whether one drug might be generally superior to another is difficult enough, but whether and how to use drugs in combination is even more perplexing. The paucity of data is reflected by the World

Received: Feb 262014 | Accepted: Feb 282014

Conflict of interest: Disclosures can be found alongside the online version of this article at www.erj.ersjournals.com

Copyright @ERS 2014 
Symposium rank of initial combination therapy as IIb-B or C (for use when intravenous prostacyclin is not available), though the evidence is more compelling (I-A) for considering sequential addition of medications if earlier treatment has been insufficiently effective. The combination of medications theoretically increases the likelihood of impact on any or all of the three recognised target mechanisms involved in PAH: the prostacyclin, endothelin and nitric oxide pathways [10, 11].

Sitbon et al. [12], in this issue of the European Respiratory Journal, have thrust to centre stage the question of how best to incorporate combination therapy. They report their experience involving 19 patients who, by any criteria (specifically a cardiac index $<2.0 \mathrm{~L} \cdot \mathrm{min}^{-1} \cdot \mathrm{m}^{-2}$, mean right atrial pressure $>20 \mathrm{mmHg}$ or pulmonary vascular resistance $\geqslant 1000 \mathrm{dyn} \cdot \mathrm{s} \cdot \mathrm{cm}^{-5}$ (preferably referred to as $\geqslant 12.5$ Wood units [13])) had severe group I PAH restricted to idiopathic, heritable or anorexigen-induced types and who were treated from the outset with incremental dosing of intravenous epoprostenol and simultaneous standardly dosed bosentan, with addition of sildenafil after 5 days. The study is described as retrospective, but the patient selection process, standardisation of assessment, treatment protocol and consistency of follow-up certainly impart a prospective flavour to the project. One presumes that this may be the consequence of a disciplined collaboration of physicians using a rigorously constructed clinical practice model within a national healthcare system that supports the concurrent initiation of three expensive medications. If so, we in the USA can only regard this arrangement with envy.

The study was neither randomised nor controlled, so we are obliged to raise the inevitable warnings (as the authors themselves did) about this potential shortcoming. Because of this limitation in the design, we need to be cautious, even sceptical, about the results. And yet it is difficult to minimise an outcome as dramatic as $100 \%$ 3-year survival in a group of $\mathrm{PAH}$ patients who were this advanced in their disease and who had an expected 3-year survival of 49\%, and all of whom achieved a stable functional class of I or II. Note that the long-term analysis excluded one patient whose baseline mean pulmonary artery pressure was $103 \mathrm{mmHg}$ and who required urgent heart-lung transplantation within 3 months of treatment, a testimony to the selection of patients with terribly advanced disease.

Would the same impressive results be observed if these patients had been compared to a control group consisting of untreated patients? That is, of course, a rhetorical question, as such a controlled study could not be performed ethically for the simple reason that untreated patients with this degree of haemodynamic compromise and symptomatic disability are well recognised as having an abysmal prognosis based upon comparison of recent [1,3] with prior [2] registries, clinical studies of monotherapeutic modalities when compared with historically expected outcomes [14-19] and universal experience. But what if the control group consisted of patients receiving treatment with a single- or double-drug regimen? In this case, the answer is less obvious, although it is reasonable to believe that a survival and symptomatic advantage would still be observed, as previous studies of these less intensive treatment strategies have not yielded $100 \%$ survival, or such dramatic improvement of symptoms or exercise tolerance. A related question is whether such a miraculous outcome will be replicated in future studies involving the same narrowly defined group of patients, whether they are performed by the same group of investigators or by others. The suspicion is justified that in all likelihood the commonly observed pattern of "the first report is the best" would once again hold true, even if a beneficial outcome continued to be observed.

So what accounts for these excellent results? One possibility is that a therapeutic approach that simultaneously impacts the three major pathophysiological pathways of $\mathrm{PAH}$ at the earliest possible point after diagnosis, albeit at an advanced stage of disease, is truly optimal. A more cynical possibility is that, in the absence of a control population, bias on the part of the investigators and/or study subjects accounts, in large part, for the reported results. While this cannot be unequivocally dismissed, it is unlikely for a couple of reasons. First, the results are simply too extreme for this to be a major explanation. Secondly, this group of experienced investigators is highly regarded and has a reputation for conscientious and self-critical analysis, i.e. if the French network of $\mathrm{PAH}$ investigators cannot be trusted to provide a reliable report to the $\mathrm{PAH}$ community, who can? Thirdly, as these patients had been recently diagnosed prior to initiation of treatment, expected survival would be poorer than if they had been previously diagnosed [20]. Finally, this group of patients was likely to have a poor outcome based on established risk models [3, 21-24].

We must consider then why triple therapy appears to be so advantageous. Here, again, there are several possibilities. Three drugs may address all of the mechanisms causing and maintaining elevated pulmonary vascular resistance and, thereby, may produce an additive or symbiotic effect, in essence leaving no stone unturned. Just as likely, however, is the possibility that one or more mechanisms promote PAH in individual patients and that the predominant causal mechanism(s) varies between patients. In that case, as we do not have an a priori means to determine which mechanism is operative in a given patient, a shotgun approach that empirically targets each mechanism (relevant or not) essentially eliminates the possibility of inadvertently missing the mark by not using the "right" medication from the start. This prospect is 
supported by the observation in this report that two patients ended up receiving only two medications after bosentan was discontinued due to elevated transaminases, yet derived equivalently beneficial outcomes as those treated with triple therapy throughout the study period. For these two patients, treatment with the two "right" medications was optimal (and more economical). A study comparing every permutation of available drugs and allowing crossover to other drugs if a salutary effect was not observed might detect comparably positive outcomes in some patients treated with fewer than three medications. A sufficiently powered study of this design is unlikely ever to occur, though the currently ongoing AMBITION study comparing the outcomes of patients treated with the upfront combination of tadalafil and ambrisentan to monotherapy with either agent is likely to shed some light on the strategy of initial multiple-drug therapy. There remains a concern that delaying initiation of an effective medication might not only delay benefit, but could prohibit ever catching up when and if the "right" medication were to be added to the regimen (especially if the patient dies in the meantime). An alternative study design might consider starting with maximum three-drug therapy and then selectively withdrawing a medication once a beneficial plateau has been achieved, in order to see if the benefit is maintained with a more conservative (and less expensive) regimen. There is, however, an understandable hesitance to alter an effective strategy once it is in place. Indeed, investigators and clinicians alike have even been reluctant to omit an ineffective medication once it has been initiated: treatment and investigational protocols using a goal-oriented strategy [25] have almost always adopted an approach of supplementing an insufficiently effective medication, rather than replacing it [26-38]. Therefore, if the current study results are considered credible, then upfront triple therapy may be the most reliable treatment strategy that we can offer our patients.

Let us circle back to the issue raised in the first sentence of this editorial. Does $100 \%$ survival at 3 years with relatively minimal symptoms constitute a cure? Clearly, it is too soon to say. The observations will need to be replicated in other patients and extended in the current study group before we can make any kind of conclusion. In the meantime, if I am discovered to have idiopathic PAH tomorrow, I would prefer to be treated with upfront triple therapy. I recognise that I may need to relocate in order for this treatment to be paid for; I am beginning to learn French now. Merci beaucoup.

\section{References}

1 Benza RL, Miller DP, Barst RJ, et al. An evaluation of long-term survival from time of diagnosis in pulmonary arterial hypertension from the REVEAL Registry. Chest 2012; 142: 448-456.

2 D’Alonzo GE, Barst RJ, Ayres SM, et al. Survival in patients with primary pulmonary hypertension: results from a national prospective registry. Ann Intern Med 1991; 115: 343-349.

3 Humbert M, Sitbon O, Chaouat A, et al. Survival in patients with idiopathic, familial, and anorexigen-associated pulmonary arterial hypertension in the modern management era. Circulation 2010; 122: 156-163.

4 Humbert M, Sitbon O, Yaici A, et al. Survival in incident and prevalent cohorts of patients with pulmonary arterial hypertension. Eur Respir J 2010; 36: 549-555.

5 Jiang X, Humbert M, Jing ZC. Idiopathic pulmonary arterial hypertension and its prognosis in the modern management era in developed and developing countries. In: Humbert M, Souza R, Simonneau G, eds. Pulmonary Vascular Disorders. Prog Respir Res 2012; 41: 85-93.

6 Jing ZC, Xu XQ, Han ZY, et al. Registry and survival study in Chinese patients with idiopathic and familial pulmonary arterial hypertension. Chest 2007; 132: 373-379.

7 Escribano-Subias P, Blanco I, Lopez-Meseguer M, et al. Survival in pulmonary hypertension in Spain: insights from the Spanish registry. Eur Respir J 2012; 40: 596-603.

8 Lee WT, Ling Y, Sheares KK, et al. Predicting survival in pulmonary arterial hypertension in the UK. Eur Respir J 2012; 40: 604-611.

9 Galie N, Corris PA, Frost A, et al. Updated treatment algorithm of pulmonary arterial hypertension. J Am Coll Cardiol 2013; 62: Suppl., D60-D72.

10 Coeytaux RR, Schmit KM, Kraft B, et al. Comparative effectiveness and safety of drug therapy for pulmonary arterial hypertension: a systematic review and meta-analysis. Chest 2014 [In press DOI: 10.1378/chest.13-1864]. Wilkins MR. Pulmonary hypertension: the science behind the disease spectrum. Eur Respir Rev 2012; 21: 19-26.

2 Sitbon O, Jaïs X, Savale L, et al. Upfront triple combination therapy in pulmonary arterial hypertension: a pilot study. Eur Respir J 2014; 43: 1691-1697.

13 Hoeper MM, Bogaard HJ, Condliffe R, et al. Definitions and diagnosis of pulmonary hypertension. J Am Coll Cardiol 2013; 62: Suppl., D42-D50.

14 Barst RJ, Rubin LJ, McGoon MD, et al. Survival in primary pulmonary hypertension with long-term continuous intravenous prostacyclin. Ann Intern Med 1994; 121: 409-415.

15 Barst RJ, Galie N, Naeije R, et al. Long-term outcome in pulmonary arterial hypertension patients treated with subcutaneous treprostinil. Eur Respir J 2006; 28: 1195-1203.

16 Provencher S, Sitbon O, Humbert M, et al. Long-term outcome with first-line bosentan therapy in idiopathic pulmonary arterial hypertension. Eur Heart J 2006; 27: 589-595.

17 Oudiz RJ, Galiè N, Olschewski H, et al. Long-term ambrisentan therapy for the treatment of pulmonary arterial hypertension. J Am Coll Cardiol 2009; 54: 1971-1981.

18 Rubin LJ, Badesch DB, Fleming TR, et al. Long-term treatment with sildenafil citrate in pulmonary arterial hypertension: the SUPER-2 study. Chest 2011; 140: 1274-1283.

19 Oudiz RJ, Brundage BH, Galie N, et al. Tadalafil for the treatment of pulmonary arterial hypertension: a doubleblind 52-week uncontrolled extension study. J Am Coll Cardiol 2012; 60: 768-774.

20 Miller DP, Gomberg-Maitland M, Humbert M. Survivor bias and risk assessment. Eur Respir J 2012; 40: 530-532. 
Benza RL, Gomberg-Maitland M, Miller DP, et al. The REVEAL registry risk score calculator in patients newly diagnosed with pulmonary arterial hypertension. Chest 2012; 141: 354-362.

22 Benza RL, Miller DP, Gomberg-Maitland M, et al. Predicting survival in pulmonary arterial hypertension. insights from the Registry to Evaluate Early and Long-Term Pulmonary Arterial Hypertension Disease Management (REVEAL). Circulation 2010; 122: 164-172.

23 Kane GC, Maradit-Kremers H, Slusser JP, et al. Integration of clinical and hemodynamic parameters in the prediction of long-term survival in patients with pulmonary arterial hypertension. Chest 2011; 139: 1285-1293.

24 Thenappan T, Shah SJ, Rich S, et al. Survival in pulmonary arterial hypertension: a reappraisal of the NIH risk stratification equation. Eur Respir J 2010; 35: 1079-1087.

25 Hoeper MM, Markevych I, Spiekerkoetter E, et al. Goal-oriented treatment and combination therapy for pulmonary arterial hypertension. Eur Respir J 2005; 26: 858-863.

26 Galie N, Rubin LJ, Hoeper MM, et al. Treatment of patients with mildly symptomatic pulmonary arterial hypertension with bosentan (EARLY study): a double-blind, randomised controlled trial. Lancet 2008; 371: 2093-2100.

27 Ghofrani HA, Galie N, Grimminger F, et al. Riociguat for the treatment of pulmonary arterial hypertension. $N$ Engl J Med 2013; 369: 330-340.

28 Pulido T, Adzerikho I, Channick RN, et al. Macitentan and morbidity and mortality in pulmonary arterial hypertension. N Engl J Med 2013; 369: 809-818.

29 Simonneau G, Rubin LJ, Galie N, et al. Addition of sildenafil to long-term intravenous epoprostenol therapy in patients with pulmonary arterial hypertension: a randomized trial. Ann Intern Med 2008; 149: 521-530.

30 Galie N, Brundage BH, Ghofrani HA, et al. Tadalafil therapy for pulmonary arterial hypertension. Circulation 2009; 119: 2894-2903.

31 Ghofrani HA, Seeger W, Grimminger F. Imatinib for the treatment of pulmonary arterial hypertension (letter). N Engl J Med 2005; 353: 1412-1413.

32 Hoeper MM, Barst RJ, Bourge RC, et al. Imatinib mesylate as add-on therapy for pulmonary arterial hypertension: results of the randomized IMPRES study. Circulation 2013; 127: 1128-1138.

33 Hoeper MM, Leuchte H, Halank M, et al. Combining inhaled iloprost with bosentan in patients with idiopathic pulmonary arterial hypertension. Eur Respir J 2006; 28: 691-694.

34 McLaughlin VV, Oudiz RJ, Frost A, et al. Randomized study of adding inhaled iloprost to existing bosentan in pulmonary arterial hypertension. Am J Respir Crit Care Med 2006; 174: 1257-1263.

35 McLaughlin VV, Benza RL, Rubin LJ, et al. Addition of inhaled treprostinil to oral therapy for pulmonary arterial hypertension: a randomized controlled clinical trial. J Am Coll Cardiol 2010; 55: 1915-1922.

36 Tapson VF, Jing ZC, Xu KF, et al. Oral treprostinil for the treatment of pulmonary arterial hypertension in patients receiving background endothelin receptor antagonist and phosphodiesterase type 5 inhibitor therapy (the FREEDOM-C2 study): a randomized controlled trial. Chest 2013; 144: 952-958.

37 Tapson VF, Torres F, Kermeen F, et al. Oral treprostinil for the treatment of pulmonary arterial hypertension in patients on background endothelin receptor antagonist and/or phosphodiesterase type 5 inhibitor therapy (the FREEDOM-C study): a randomized controlled trial. Chest 2012; 142: 1383-1390.

38 Simonneau G, Torbicki A, Hoeper MM, et al. Selexipag: an oral, selective prostacyclin receptor agonist for the treatment of pulmonary arterial hypertension. Eur Respir J 2012; 40: 874-880. 